\title{
Patient Characteristics Associated With a Successful Response to Nurse-Led Care Programs Targeting the Oldest-Old: A Comparison of Two RCTs
}

\author{
Nienke Bleijenberg, RN, PhD • Lorenz Imhof, RN, PhD • Romy Mahrer-Imhof, RN, \\ $\mathrm{PhD}$ • Margaret I. Wallhagen, RN, PhD • Niek J. de Wit, MD, PhD • \\ Marieke J. Schuurmans, RN, PhD
}

\section{ABSTRACT}

Keywords

oldest-old, community-based

nurse-led care

programs,

randomized controlled trial
Background: To improve the effectiveness of community-based care programs, especially those targeting the oldest-old population $(80+)$, data are needed that elucidate those factors associated with a successful response to the intervention. Two comparable nurse-led care programs have been evaluated in two large randomized controlled trials (RCTs), one in Switzerland and one in the Netherlands.

Aims: To identify common patient characteristics that are related to a successful response to proactive nurse-led care, we explored if and to what extent, identical factors were present in both study populations.

Methods: A secondary data analysis using trial data from the intervention group of both RCTs was conducted. The study sample consisted 461 older adults, 230 from the U-PROFIT trial (the Netherlands) and 231 from the HPC trial (Switzerland). The mean age of the total sample was 85.1 years (SD 3.7). The UPROFIT intervention, delivered by registered nurses, included a frailty assessment and a comprehensive geriatric assessment (CGA) at home followed by an individualized evidence-based care plan, care coordination, and follow-up. The HCP intervention was delivered by advanced practice nurses consisting of four home visits and three phone calls, and was guided by the principles of health promotion, empowerment, partnership, and family-centeredness. A successful response was defined as "stable" or "no decline" in daily functioning at follow-up. Daily functioning was measured with 13 items of activities of daily living and instrumental activities of daily living. Multivariate logistic regression models were applied to calculate the association between individual characteristics and a successful response.

Results: Almost half of the participants in the U-PROFIT trial (50.9\%), and two-thirds (65.7\%) of the participants in the HCP trial had a successful response at follow-up. Fewer comorbidities and a better self-rated health had the strongest predictive value for benefiting from the intervention $(\mathrm{OR}=0.83$ [95\% Cl 0.66-1.03], and OR = 1.5 [95\% Cl 0.92-2.45]), respectively.

Linking Evidence to Action: Two large RCTs demonstrated that a preventive nurse-led care program can preserve daily functioning in the oldest-old population. Older people with few comorbidities and higher self-rated health had a higher likelihood of a positive outcome. Unraveling the characteristics associated with a successful response provides important information for further refining and targeting an intervention to obtain maximum effectiveness. More effort is needed to modify interventions for the oldest-old with multiple morbidities and low levels of education.

\section{INTRODUCTION}

Nations throughout the world are experiencing a rapid growth in the numbers of persons aged 65 and older with a particularly rapid increase in those aged 80 years and over (Rechel et al., 20I3). In the oldest-old population, the prevalence of multimorbidity, defined as $>2$ comorbidities, is $8 \mathrm{I} .5 \%$ with a mean number of comorbidities of 3.6 (between $74 \%$ and $80 \%$; Barnett et al., 20I2). Major consequences of multimorbidity are functional decline, poor quality of life, and high healthcare costs (Chatterji, Byles, Cutler, Seeman, \& Verdes, 2015; Prince 
et al., 20I5). Comprehensive changes in healthcare systems are urgently needed to provide adequate, efficient care while reducing healthcare budgets (Markle-Reid et al., 2006; Prince et al., 20I5). In Europe, a fundamental shift toward proactive primary care emphasizes prevention or reduction of functional decline in older adults in order to maintain independent living as long as possible (World Health Organization [WHO], 20I5).

Over the last decade, several integrated, multidisciplinary care programs designed to improve patients' health outcomes promote multidisciplinary collaboration, and reduced costs have been evaluated among community-dwelling older adults (Beswick et al., 2008; Markle-Reid, Browne, \& Gafni, 20I3). Broadly, these programs consist of case finding strategies to identify patients at risk, assessments of needs, care planning, care coordination, and follow-up led by a nurse or case manager (Metzelthin et al., 20I3; Stall, Nowaczynski, \& Sinha, 20I4). However, very few are targeted at the oldest-old and the results are inconclusive (Fairhall et al., 2012; Metzelthin et al., 20I3; Stall et al., 20I4). Moreover, details regarding why a program was successful or not and the underlying mechanisms of the intervention-outcome relationship are often lacking (MarkleReid et al., 2006). Furthermore, less is known about whether the oldest-old population benefits from preventive care programs in terms of daily functioning and who benefits the most. To provide data that can optimize the design and implementation of preventive community-based care programs targeted to those who will benefit the most, the factors underpinning a successful or positive response to a given intervention need to be elucidated.

To begin to address the knowledge gap in this area, we leveraged data from two comparable community-based nurse-led care programs that were developed, implemented, and evaluated in two large randomized trials, one in the Netherlands (Bleijenberg et al., 20I6) and one in Switzerland (Imhof, Naef, Wallhagen, Schwarz, \& Mahrer-Imhof, 20I2). In the Utrecht Proactive Frailty Intervention Trial (U-PROFIT trial), the costeffectiveness of a proactive primary care program was evaluated in a three-armed cluster randomized trial that included over 3,000 older adults (6o+ years old) in the Netherlands. One of the interventions consisted of screening and monitoring instrument followed by a multicomponent nurse-led care program. As compared to the control group, the proactive primary care strategy maintained daily functioning at I-year follow-up and improved daily functioning in high-educated older participants as compared to the control group (Bleijenberg et al., 20I6). A cost-effectiveness analysis demonstrated that the intervention was cost-effective due to the fact that participants in the intervention group spend less days in a nursing home compared to the control group participants (submitted work).

Moreover, the program was well regarded by the participating older adults, general practitioners, and nurses (Bleijenberg et al., 20I3; Bleijenberg, Boeije, Onderwater, \& Schuurmans, 20I5). Similarly, Imhof and coworkers (2012) investigated the effectiveness of an in-home health consultation program (HCP) delivered by advanced practice nurses among 46r older adults (8o+ years old) in Switzerland. The HCP program was effective in reducing adverse outcomes such as falls, acute events, and hospitalizations (Imhof et al., 20I2).

Although the results of patient level outcomes have been reported, little is known about the characteristics that contributed to a successful outcome in the daily functioning domain in the oldest-old. This knowledge would be valuable in order to target the intervention to those who are most likely to benefit. Therefore, the aim of this study was to identify patient characteristics that are related to successful response to the proactive nurse-led care provided in both intervention trials. We explore if, and to what extent, these characteristic were found in both populations so as to improve generalizability. We hypothesized that the oldest-old who had a better health status at baseline would be more likely to benefit from proactive nurse-led care as compared with those with a lower health status.

To better understand the mechanisms underlying the impact of the interventions on daily functioning, the International Classification of Functioning, Disability and Health (ICF) was used as the theoretical framework for this study (WHO, 200I). The ICF schema outlined by ICF is a biopsychosocial model that highlights the way in which biological, individual, and social factors each contribute to an individual's activity and function (Figure Si, available with the online version of this article). Thus, this framework can facilitate an understanding of the factors influencing the changes that occur in health and functioning from a broad perspective.

\section{METHODS}

\section{Design}

A secondary, pooled data analysis using data from all participants enrolled in the intervention group of both randomized controlled trials (RCTs) who were 80 years of age and older. The purpose was to identify the characteristics associated with a successful response to both interventions. In this study, a successful response was defined as "stable" or "no decline" in daily functioning (e.g., preserved daily functioning at follow-up).

\section{Participants and Procedure}

The U-PROFIT trial was conducted in and around Utrecht, the fourth biggest city in the Netherlands. A total of 39 clusters of general practices, over 3,000 older people, and more than 350 caregivers participated in the U-PROFIT trial. Eligible patients aged 60 years or older were screened for the following criteria: multimorbidity (based on International Classification of Primary Care [ICPC] registration of the EMR system, a frailty index was constructed using the accumulated deficit approach; Drubbel et al., 20I3), polypharmacy (defined as chronic use of five or more different medications), and a consultation gap (defined as not having consulted the GP in the past 3 years except for a yearly influenza vaccination). Eligible participants were invited by their GP to participate. Informed consent was obtained from all participants. The U-PROFIT trial was approved by the Institutional Review Board of the University Medical Center 
Utrecht (UMCU) with protocol ID Io-I49/O and was registered in the Netherlands Trial Register: NTR2288 (Bleijenberg et al., 20I6).

The HCP study was conducted in one of the major cities in the German-speaking part of Switzerland. It involved a convenience sample of German-speaking, community-dwelling persons aged 80 years and older who were cognitively able to understand and consent to the study. Various health organizations such as local hospitals, home care organizations, church social services, community nurses, and family physicians extended the invitation to participate in the study to I,I82 potential participants. An additional I,43I letters of invitation were sent to people's homes. Fifty-five percent $(n=2,6 \mathrm{I} 3)$ of the city's inhabitants aged 80 and older and living at home were invited to take part in the study. The response rate was $2 \mathrm{I} .5 \%$, with 562 persons expressing an interest in the study. A total of 46 I of these fulfilled the inclusion criteria and gave consent to participate in the study (Imhof et al., 20I2).

\section{Interventions}

U-PROFIT intervention. After a thorough review of the literature, we concluded that the most promising intervention components would be those derived from the Chronic Care Model (CCM), a framework for redesigning practice to enhance the quality of care (Bleijenberg et al., 2013). Therefore, the proactive primary care strategy consisted of the following multiple components, including a frailty screening based on routine primary care data followed by a multicomponent nurseled care program. In short, patients at risk for adverse events were identified by a screening instrument that was installed on the computer of the general practitioner (GP; Drubbel et al., 20I3). This instrument generated a list every three months of people at risk based on the inclusion criteria described earlier. Next, patients identified by this instrument received a postal questionnaire that assessed the level of frailty, complexity of care needs, and well-being. Frailty was measured using the Groningen Frailty Indicator (GFI; Steverink, Slaets, Schuurmans, \& Van Lis, 200I), a I5-item questionnaire that measures frailty on multiple domains. Patients with a GFI score of $\geq 4$ received a comprehensive geriatric assessment (CGA) at home from Advanced Practice registered nurses specially trained in primary care. The nurses developed a tailored care plan, conducted follow-up visits, closely collaborated with the GP and other healthcare professionals, and coordinated the care. As described elsewhere (Bleijenberg et al., 2013), the program was developed by a multidisciplinary team that included an expert group of older adults that improved the acceptability in clinical practice. Evidence-based care plans for II geriatric conditions, such as falls, urinary incontinence, cognition, and loneliness, were developed for the nurses (all available upon request, example cognition provided in Figure $\mathrm{S}_{2}$, found with online version of this article).

HCP intervention. All participants received healthcare services as usual provided by community health nurses (23\%) and physicians (97\%). Persons in the intervention group took part in a complementary 9-month in-home HCP, provided by four experienced Advanced Practice Nurses (APNs). The intervention included four home visits after $4,12,24$, and 36 weeks, and three telephone calls after 8, 8 , and 30 weeks. Total intervention time per participant averaged 4 hours.

The HCP was guided by the principles of health promotion, empowerment, partnership, and family-centeredness as described in behavioral change theories (Imhof et al., 2012). The intervention included a clinical assessment of health and family situation, education and counseling regarding specific health concerns, daily management of symptoms or illness, and organization of family or professional care, as well as specific skills training. At follow-up visits, an evaluation of the previous sessions was also conducted. Interventions were customized to the participants' needs and based on evidence-based guidelines. All interventions included an action plan with concrete activities to address health or family concerns. This action plan was continuously developed and evaluated with the patient and served as a basis for further interventions (Imhof, Naef, Mahrer-Imhof, \& Petry, 20II). Details of the U-PROFIT and HCP interventions, components, and outcomes are described in Table I.

Outcome and measurements. The primary outcome of the current study was daily functioning because this is a central component of the ICF, indicates the ability to carry out an activity, and is critical to an older adult's ability to remain independent and age in place. This was measured with the modified Katz-I5 in the U-PROFIT trial and the Older American Resources and Service Scale (OARS) in the HCP trial. The modified Katz-I5 is a self-reported questionnaire that consists of six ADL items (bathing, dressing, toileting, continence, eating, and grooming), seven IADLs (shopping, transfer, traveling, household, preparing a meal, using the telephone, managing finances, and medicines), and one walking item (Weinberger et al., I992). All items were scored as zero (independent) or one (dependent), leading to a range from o to I5 with a higher score indicating higher level of dependency. The modified Katz-I5 is demonstrated to be a reliable, valid instrument for the prediction of unfavorable health outcomes in community-dwelling older people (Laan et al., 20I4).

The OARS is a valid and reliable questionnaire to assess the overall personal functioning in activities of daily living (Fillenbaum \& Smyer, I98I). The German version of the questionnaire was used in the European Study of Adult Well-Being (Weber, 2002). The OARS has a three-level outcome: Zero indicates disabled, one indicates with some help, and two indicates independent. The score ranges between o (completely dependent) and 28 (completely independent).

To facilitate the merging of the primary outcome of the two studies, we used only the items of Katz-I5 and OARS that were identical. Katz items "transfer" and "continence," and the OARS items "going to bed," and "a person helping you" were not present in both questionnaires and were therefore 
Table 1. Intervention Details UPROFIT and HCP Trial

\begin{tabular}{|c|c|c|}
\hline & U-PROFIT intervention (the Netherlands) & HCP intervention (Switzerland) \\
\hline & Bleijenberg et al., 2012 & Imhof et al., 2012 \\
\hline Design \& follow-up & $\begin{array}{l}\text { Single-Blind Three-armed cluster } \\
\text { randomized trial, } 12 \text { months follow-up }\end{array}$ & $\begin{array}{l}\text { Randomized Controlled Trial, } 9 \text { months } \\
\text { follow-up }\end{array}$ \\
\hline \multirow[t]{2}{*}{ Inclusion criteria } & $\begin{array}{l}60+\text { and either one or more of the following } \\
\text { criteria: }\end{array}$ & $80+$ \\
\hline & $\begin{array}{l}\text { (1) Multimorbidity (defined as a frailty } \\
\text { index score of } \geq 0.20 \text { ) } \\
\text { (2) Polypharmacy (chronic use of five or } \\
\text { more different medications) } \\
\text { (3) 3. Care gap in primary care of three } \\
\text { or more years (defined as not having } \\
\text { consulted the GP in the past } 3 \text { years, } \\
\text { except for the yearly influenza). }\end{array}$ & $\begin{array}{l}\text { Various healthcare organizations, local } \\
\text { hospitals, church social services and } \\
\text { community nurses and family physicians } \\
\text { extended the invitation to participate }\end{array}$ \\
\hline$N$ included in trial & $N=3,092$ & $N=461$ \\
\hline \multirow{2}{*}{$\begin{array}{l}N \text { included in } \\
\text { intervention }\end{array}$} & $N=1,287$ aged $60+$ & $N=231$ \\
\hline & $N=273$ aged $80+$ & \\
\hline Measurements & $\begin{array}{l}\text { 0-6-12 months using questionnaires, and } \\
\text { electronic medical record (EMR) data. }\end{array}$ & $\begin{array}{l}\text { 0-3-6-9 months using questionnaires and } \\
\text { phone calls }\end{array}$ \\
\hline Primary outcome & $\begin{array}{l}\text { Daily Functioning measured with Katz-15 } \\
\text { ADL/IADL index }\end{array}$ & $\begin{array}{l}\text { Quality of life (World Health Organization } \\
\text { Quality of Life Assessment short version, } \\
\text { WHOQOL-Bref, domains: physical, } \\
\text { psychological, social, environmental) }\end{array}$ \\
\hline Secondary outcomes & $\begin{array}{l}\text { - Quality of life (RAND-36 dimensions; } \\
\text { physical, social, psychological, and } \\
\text { vitality) and EuroQol (EQ-5D) } \\
\text { - Mortality } \\
\text { - Health Care Consumption: GP } \\
\text { consultation visits, GP telephone } \\
\text { visits, Out-of-hours GP visits, Hospital } \\
\text { admission, Nursing home admissions, } \\
\text { Emergency department visits, } \\
\text { Caregiver burden measured with } \\
\text { Self-Rated Burden (VAS) and } \\
\text { Carer-Qol } \\
\text { - Satisfaction with primary care } \\
\text { - } \text { (questionnaire) } \\
\text { - Self-reported diseases } \\
\text { (questionnaire) } \\
\text { - Frailty level: Groningen Frailty } \\
\text { Indicator (GFI) } \\
\text { - Self-rated health (VAS 10-point scale) }\end{array}$ & $\begin{array}{l}\text { - Independence in daily activities } \\
\text { (Older Americans Resources and } \\
\text { Services, OARS) } \\
\text { - Social support, self-efficacy, family } \\
\text { functioning } \\
\text { - } \text { A MGSA (Timed Up and Go Test, } \\
\text { MNA, GDS (4 items) }\end{array}$ \\
\hline $\begin{array}{l}\text { Intervention } \\
\text { components }\end{array}$ & $\begin{array}{l}\text { The intervention was delivered by registered } \\
\text { nurses in primary care. The intervention } \\
\text { components are: }\end{array}$ & $\begin{array}{l}\text { The in-home HCP was provided by APNs* } \\
\text { and was guided by the principles of health } \\
\text { promotion, empowerment, partnership, } \\
\text { and family-centeredness. }\end{array}$ \\
\hline & & (Continued) \\
\hline
\end{tabular}


Table 1. Continued

\begin{tabular}{|c|c|c|}
\hline & U-PROFIT intervention (the Netherlands) & HCP intervention (Switzerland) \\
\hline & Bleijenberg et al., 2012 & Imhof et al., 2012 \\
\hline & $\begin{array}{l}\text { - Frailty Assessment } \\
\text { - Comprehensive Geriatric Assessment } \\
\text { - } \text { at home } \\
\text { - Tailor-made care plan } \\
\text { - Follow-up visits } \\
\text { - Care coordination }\end{array}$ & $\begin{array}{l}\text { After a comprehensive geriatric assessment, } \\
\text { participants were randomly assigned. An } \\
\text { action plan was developed. }\end{array}$ \\
\hline Intervention intensity & $\begin{array}{l}\text { At least one CGA at home. Next, based on } \\
\text { the needs additional visits were } \\
\text { conducted. The intervention was } \\
\text { personalized to the individual. }\end{array}$ & $\begin{array}{l}\text { Four in-home visits and three phone calls } \\
\text { from Advanced Practice Nurses (APNs) }\end{array}$ \\
\hline Training of the nurses & $\begin{array}{l}N=21 \text { Registered Nurses were extensively } \\
\text { trained in a 6-week post-Bachelor level } \\
\text { geriatrics/gerontology training of } 48 \\
\text { hours. The nurses had monthly training } \\
\text { meetings and feedback. }\end{array}$ & $\begin{array}{l}N=4 \text { APNs were trained: } 1 \text { week training } \\
\text { session of } 42 \text { hours/ongoing detailed } \\
\text { documentation combined with regular } \\
\text { clinical briefing sessions during the } \\
\text { intervention period. }\end{array}$ \\
\hline \multicolumn{3}{|l|}{ Results trial } \\
\hline & $\begin{array}{l}\text { * Small, but significant result on daily } \\
\text { functioning. High educated people } \\
\text { improved daily functioning. } \\
\text { * No effects on QoL, healthcare } \\
\text { consumption except for GP visits. } \\
\text { A cost utility analysis from a societal } \\
\text { perspective was performed, and showed } \\
\text { that the intervention was cost-effective } \\
\text { due to the fact that participants in both } \\
\text { intervention groups reported less } \\
\text { admission days in a nursing home } \\
\text { compared to the control group } \\
\text { participants. }\end{array}$ & $\begin{array}{l}\text { * No significant results on any dimension } \\
\text { of the World Health Organization Quality } \\
\text { of Life questionnaire. } \\
{ }^{*} \text { At } 9 \text { months a significant result was } \\
\text { reported in self-reported acute events } \\
(\mathrm{RR}=.70, \mathrm{NNT}=4.3, p=.001 \\
\text { falls }(\mathrm{RR}=71, \mathrm{NNT}=7.1, p=.003 \\
\text { hospitalizations (RR }=.70, \mathrm{NNT}=10.0 \text {, } \\
p=.03)\end{array}$ \\
\hline
\end{tabular}

not used in the combined outcome. Thus, the primary outcome was calculated based on the following I3 items: Bathing, dressing, toileting, preparing a meal, grooming, walking, shopping, household tasks, traveling, using the telephone, eating, managing medications, and managing finances.

The score of the Katz-I3 items was transformed in line with scale of the OARS: Disabled had a score of zero, and independent had a score of two. In this study, successful response was defined when older people experienced no decline (stable) or improvement in daily functioning after follow-up compared with their baseline level of functioning.

Other measures. The following characteristics were selected as potentially relevant predictors based on the literature and clinical reasoning and measured at baseline using self-reported questionnaires. Demographics measured in both studies were age, gender, living situation (alone or with others), and the level of education. Low education was defined as primary school or less; average education was defined as secondary school; and high education was defined as more than secondary school. Factors related to health status such as the number of chronic conditions (e.g., diabetes, heart failure, stroke, brain damage), urinary incontinence, mood and depressive feelings, anxiety, weight loss, hearing loss, vision impairment, walking aid, falls, hospitalized one year ago, pain, self-rated health (scale o-ro), and number of medications in chronic use were measured. Polypharmacy was defined as using five or more medications in chronic use (Gnjidic et al., 20I2).

\section{Statistical Analysis}

Characteristics of both study populations at baseline were described using descriptive statistics. Missing data rarely occur at random and a complete case analysis (deletion of patient with one or more missing values) leads to loss of statistical 
power and to biased results (Donders, Van Der Heijden, Stijnen, \& Moons, 2006). On the primary outcome, I22 persons $(26.5 \%)$ had missing values $(n=69$ [30\%] in U-PROFIT and $n=53$ [22.9\%] in the HCP trial). We compared and tested the characteristics (age, gender, education, and baseline score daily functioning) of those who were lost to follow-up with the participants who completed the study using chi-square for dichotomous outcomes and independent sample $t$-test for continuous outcomes and observed no significant differences (data not shown). Therefore, we decided to impute the missing values on the primary outcome by multiple imputation ( $m=\mathrm{IO}$ ). Age, gender, and baseline health status were used as imputation variables. The analyses described below were performed on the imputed dataset.

The analyses were conducted in several steps. First, univariate associations between the predictors and successful response (stable or improvement on the Katz-I3 or OARSI3) were estimated using logistic regression analysis in both datasets separately. Age, the number of medications taken, and the number of chronic conditions reported were analyzed as continuous variables; all other variables were included as dichotomous or categorical variables. Multicollinearity was tested using the Variance Inflation Factor and no collinearity was observed. Second, a multivariate logistic regression analysis was performed on the pooled dataset (merged dataset). No selection was made based on these univariate estimations since selection of predictors based on univariate statistics may result in unstable prediction models (Harrell, Lee, \& Mark, I996). We therefore included all candidate predictors in a multivariate backward stepwise selection logistic regression model. We corrected for the baseline Katz-I3 or OARS-I3 score because it is known that a baseline score is associated with the outcome. The final model included those predictors identified by the backward model using Akaike's Information Criterion (AIC) as a cutoff point, which corresponds to selection based on a $p$ value of .I57 (Akaike, I974). Finally, the same predictors were included in the multivariate logistic regression model stratified by country. The results are reported as odds ratios (OR) with $95 \%$ confidence intervals (CI). The ability of the model to discriminate between older persons with and without a successful response was determined with the area under the Receiver Operating Characteristics (ROC) curve (c-statistics). All analyses were performed using IBM SPSS Statistics version 2I (IBM Corp., Armonk, NY).

\section{RESULTS}

Demographics and clinical characteristics of the participants of both intervention groups are shown in Table 2 . The mean age of the sample was 85 years, was comprised of more females than men $(>63 \%)$, and the majority were living independently alone (> 51\%). Differences in baseline characteristics of the two study populations were observed for the level of education; $49.6 \%$ of the older adults in the U-PROFIT study had low education versus $23.4 \%$ of the HCP participants. The num- ber of participants with diabetes and pulmonary diseases was higher in the U-PROFIT trial compared with the HCP trial. Compared with the HCP trial, participants in the U-PROFIT trial reported substantial more problems with walking the stairs (77\% vs. $6.5 \%)$, more frequent use of a walking aid $(67.2 \%$ vs. $42 \%$ ), using more medications (mean 7.7 vs. 4.4 ), and experiencing hearing impairment more frequently $(60.9 \%$ vs. $33.8 \%$ ). Over $80 \%$ of the participants in the HCP trial reported pain compared with $46 \%$ of the participants in U-PROFIT. In total, 82 (50.9\%) participants in the U-PROFIT trial, and II7 $(65.7 \%)$ in the HCP trial had a successful response at follow-up.

Table 3 shows the univariate association between characteristics of the participants from both trials. In U-PROFIT, fewer morbidities $(p=.03)$, pain $(p=.04)$, and better self-rated health $(p=.02)$ were significantly associated with a successful response, defined as stable or improvement on daily functioning. In the HCP data, polypharmacy $(p=.02)$, fewer falls $(p=. \mathrm{OI})$, and better self-rated health $(p=.03)$ were significantly associated with stable or improved functioning.

We found a moderate to strong correlation between polypharmacy and multimorbidity in our study: Pearson's $r$ correlation $0.42(p \leq .00 \mathrm{I})$. To limit the number of predictors in the multivariate model and avoid over fitting, we decided to include multimorbidity, defined as the total number of chronic diseases (range o-7) in the multivariate pooled analysis. Whether to include one or the other variable was determined by testing its effect. There were no major differences in the model's performance when either multimorbidity or polypharmacy was included. In the pooled dataset, $56.1 \%$ did not decline on the primary outcome of daily functioning. Using a walking aid, better self-rated health, fewer morbidities, and better functional status at baseline were the strongest, although not significant, predictors for a positive response to either intervention (Table 4). Self-rated health and less comorbidity seem the strongest predictors. The model's c-statistic (AUC) was 0.6884 (95\% CI [0.572-0.676]) indicating a moderate discriminative ability between persons who are likely to benefit from the intervention and persons who are less likely to benefit from the intervention.

Finally, multivariate models were performed and stratified by population. Table 5 shows the odds ratios (ORs) with $95 \%$ confidence interval (CI) per predictor per study population. Except for gender, the ORs were comparable across both populations, and better self-rated health had the strongest predictive value. The OR of successful response for high versus low educated participants in U-PROFIT was I.3 (95\% CI [0.53-3.I6]), and 2.26 (95\% CI [0.72-7.I]) in the HCP trial.

\section{DISCUSSION}

In this secondary data analysis, we were able to pool data from two large intervention trials to identify characteristics of the oldest-old $(80+)$ that were related to a positive response, as measured by functional status, to preventive nurse-led care programs. Both nurse-led care programs were able to preserve 
Table 2. Baseline Characteristics Frail Participants Both Studies

\begin{tabular}{|c|c|c|}
\hline & U-PROFIT $N=230$ & $\mathrm{HCP} N=231$ \\
\hline Age, mean $(S D)$ & $84.9(3.5)$ & $85.2(3.9)$ \\
\hline Female, $n(\%)$ & $147(63.9)$ & $167(72.3)$ \\
\hline \multicolumn{3}{|l|}{ Education, $n(\%)$} \\
\hline Low & $114(49.6)$ & $54(23.4)$ \\
\hline Average & $87(37.8)$ & $148(64.1)$ \\
\hline High & $28(12.2)$ & $29(12.6)$ \\
\hline \multicolumn{3}{|l|}{ Living situation, $n(\%)$} \\
\hline Alone & $118(51.3)$ & $159(68.8)$ \\
\hline Together with others & $112(48.7)$ & $72(31.2)$ \\
\hline Number of chronic conditions, ${ }^{a}$ mean (SD) & $1.6(1.2)$ & $0.99(0.93)$ \\
\hline Number of medications in chronic use, mean (SD) & $7.7(2.5)$ & $4.4(3.2)$ \\
\hline Diabetes, $n(\%)$ & $63(27.4)$ & $22(9.5)$ \\
\hline Heart failure (heart insufficiency), n (\%) & $66(28.7)$ & $57(24.7)$ \\
\hline Pulmonary diseases (asthma/COPD), n (\%) & $52(22.6)$ & $19(8.2)$ \\
\hline Depressive feelings, ${ }^{\mathrm{b}} n(\%)$ & $37(16.1)$ & $46(19.9)$ \\
\hline Problems with walking on stairs, $n(\%)$ & $177(77)$ & $15(6.5)$ \\
\hline Walking aid, $n(\%)$ & $154(67.2)$ & $97(42)$ \\
\hline Weight loss, $n(\%)$ & $40(17.4)$ & $39(17.2)$ \\
\hline Hearing loss, $n(\%)$ & $140(60.9)$ & $78(33.8)$ \\
\hline Vision problems, $n(\%)$ & $110(47.8)$ & $98(42.4)$ \\
\hline Urinary incontinence, $n(\%)$ & $120(52.2)$ & $61(26.4)$ \\
\hline Falls (one or more per year), $n(\%)$ & $80(34.8)$ & $86(37.2)$ \\
\hline Cognitive problems ${ }^{c}$ & $153(66.5)$ & $66(28.5)$ \\
\hline Feelings of loneliness (some, severe) & $138(60)$ & NA \\
\hline Social support, less than 1 contact a month & NA & $46(19.9)$ \\
\hline Self-rated health, excellent, very good or good, $n(\%)$ & $148(48.3)$ & $143(61.9)$ \\
\hline Quality of life, ${ }^{\mathrm{d}}$ between 0 and 10 , mean $(S D)$ & $6.9(1.1)$ & $7.0(1.8)$ \\
\hline Hospitalized in the last 12 months, $n(\%)$ & $53(23)$ & $79(34.2)$ \\
\hline Having pain, $n(\%)$ & $106(46.1)$ & $188(81.4)$ \\
\hline Successful response, ${ }^{\mathrm{e}} n(\%)$ & $82(50.9)$ & $117(65.7)$ \\
\hline Katz-13 (U-PROFIT), OARS-13 (HCP), median (IQR) & $22(18-24)$ & $24(22-25)$ \\
\hline \multicolumn{3}{|c|}{$\begin{array}{l}\text { Note. NA = not asked. } \\
\text { aList of seven chronic conditions: brain, vascular/heart failure, dementia, osteoarthritis, DM, Asthma/COPD, cancer. } \\
\text { bU-PROFIT: Do you have depressive feelings (yes, moderate, no). HCP: GDS 4, Geriatric Depression Scale Short Version, Score 0-6. A score > = } 1 \text {. } \\
\text { "In U-PROFIT, cognition was subjectively measured with one question: do you have memory problems: yes, a lot, yes, some, no. In HCP "did your forgetfulness } \\
\text { significantly increase in the last } 3 \text { months": yes, very and yes, rather are reported. } \\
\text { d WHOQOL Score } 0-100=>\text { mean }(S D)=69.6 \text { (17.9). } \\
\text { e Successful response: Improvement or stable in daily functioning after follow-up measured with Katz-13 or OARS-13. } \\
\text { f UPROFIT: Katz-13 and OARS-13 score between } 0 \text { and 26. Numbers based complete cases. HCP } n=53(22.9 \%) \text { missing, U-PROFIT } n=69(30 \%) \text { missing. }\end{array}$} \\
\hline
\end{tabular}


Table 3. Univariate Associations Between Potential Predictors and a Successful Response ${ }^{a}$

\begin{tabular}{|c|c|c|c|c|}
\hline & U-PROFIT OR (95\% Cl) & $p$ value & HCP OR (95\% Cl) & $p$ value \\
\hline Age & $0.97(0.88-1.06)$ & 0.45 & $0.97(0.89-1.06)$ & .48 \\
\hline Gender & $0.66(0.34-1.30)$ & 0.23 & $1.32(0.66-2.60)$ & .44 \\
\hline Male & 0 & & 0 & \\
\hline Educational level- Average & $1.09(0.58-2.05)$ & 0.78 & $0.81(0.42-1.56)$ & .53 \\
\hline Educational level- High & $1.30(0.53-3.16)$ & 0.56 & $2.26(0.72-7.1)$ & .16 \\
\hline Educational level -Low & 0 & & 0 & \\
\hline Living situation, together with others & $0.62(0.33-1.16)$ & 0.13 & $1.025(0.53-1.98)$ & .94 \\
\hline Alone & 0 & & 0 & \\
\hline Number of chronic conditions ${ }^{\circ}$ & $0.71(0.52-0.97)$ & 0.03 & $0.83(0.58-1.19)$ & .32 \\
\hline No & 0 & & 0 & \\
\hline Number of medications & $0.96(0.85-1.10)$ & 0.56 & $0.89(0.81-0.98)$ & .02 \\
\hline No & 0 & & 0 & \\
\hline Hospitalized last year & $0.92(0.45-1.90)$ & 0.82 & $0.71(0.37-1.35)$ & .29 \\
\hline No & 0 & & 0 & \\
\hline Weight loss & $1.23(0.55-2.76)$ & 0.61 & $0.81(0.34-1.91)$ & .63 \\
\hline No & 0 & & 0 & \\
\hline Vision loss & $0.73(0.39-1.36)$ & 0.32 & $1.08(0.58-2.01)$ & .81 \\
\hline No & 0 & & 0 & \\
\hline Hearing loss & $1.32(0.69-2.51)$ & 0.41 & $1.01(0.49-2.07)$ & .98 \\
\hline No & 0 & & 0 & \\
\hline Pain & $0.43(0.19-0.97)$ & 0.04 & $0.90(0.39-2.05)$ & .80 \\
\hline No & 0 & & 0 & \\
\hline Urinary incontinence & $0.79(0.43-1.48)$ & 0.47 & $1.26(0.61-2.60)$ & .53 \\
\hline No & 0 & & 0 & \\
\hline Anxiety & $0.47(0.08-2.63)$ & 0.39 & $1.27(0.52-3.14)$ & .60 \\
\hline No & 0 & & 0 & \\
\hline Falls (HCP) & NA & & $0.44(0.23-0.84)$ & .012 \\
\hline No falls & & & 0 & \\
\hline Self-rated health, excellent, or good & $2.26(1.12-4.55)$ & 0.022 & $2.01(1.07-3.79)$ & .031 \\
\hline Moderate to bad & 0 & & 0 & \\
\hline Mood/depressive feelings & $0.66(0.35-1.25)$ & 0.20 & $0.86(0.40-1.84)$ & .69 \\
\hline No mood or depressive feelings & 0 & & 0 & \\
\hline Using a walking aid & $0.66(0.35-1.26)$ & 0.21 & $0.54(0.29-1.02)$ & .06 \\
\hline Not using a walking aid & 0 & & 0 & \\
\hline
\end{tabular}

a Successful response (1) was defined as having the same or a lower Katz/OARS score (indicating a better level of daily functioning) at follow-up. Unsuccessful response was defined as 0 and indicated a score of 1 or more on the Katz-13 or OARS-13 after follow-up, indicating a lower level of daily functioning, or admitted to assisted living facility, nursing home, or death. ${ }^{\circ}$ Multimorbidity was defined as the number of comorbidities, based on seven conditions: 1. Brain, 2. Vascular damage, heart failure, 3. Dementia, 4. Osteoarthritis, 5. DM, 6. Asthma/COPD, 7. Cancer. 
Table 4. Logistic Regression, Results From Pooled Dataset (U-PROFIT and HCP, $N=461$ )

\begin{tabular}{|c|c|c|c|}
\hline & OR & $95 \% \mathrm{Cl}$ & $p$ value \\
\hline Age & 0.99 & $0.93-1.05$ & .68 \\
\hline Female & 1.04 & $0.64-1.71$ & .86 \\
\hline Using a Walking Aid & 0.78 & $0.40-1.53$ & .46 \\
\hline Better self-rated health & 1.50 & $0.92-2.45$ & .10 \\
\hline Number of comorbidities ${ }^{a}$ & 0.83 & $0.66-1.03$ & .09 \\
\hline Functional status at baseline ${ }^{b}$ & 0.98 & $0.88-1.12$ & .85 \\
\hline
\end{tabular}

Note. Analysis performed on imputed dataset. Selection of predictors are based on the AIC $<0.157$ in a backward model.

a Higher number of comorbidities has lower odds of benefiting from the intervention.

${ }^{\mathrm{b}}$ Baseline Katz-13 or OARS-13 is functional status at baseline. Constant $=5.597$.

or improve daily functioning in the oldest old population (mean age 85). Half of the participants in the U-PROFIT trial (50.9\%), and two thirds $(65.7 \%)$ of the participants in the HCP trial had a successful response at follow-up. Better self-rated health and less morbidity were the strongest predictor of a positive response.

At follow-up, I99 (58.7\%) of the participants in both trials either maintained or improved their functional status after the intervention period. In the U-PROFIT trial, the annual decline in daily functioning in the control group, as measured on the Katz-I5, was 0.23 (crude estimate between baseline and I2 months follow-ups, unadjusted). Comparing the natural decline in daily functioning among the oldest-old participants in these two studies is challenging, given the fact that different instruments were used. However, taking these limitations into account, the results demonstrated that both interventions were effective, and that the oldest-old population could benefit from nurse-led care in terms of slower or reduce functional decline.

The predictors related to a successful response correspond with the domains of the ICF such as personal factors, health condition, environmental factors, and participation that contribute to functional capacity (WHO, 200I). Self-rated health (SRH) is a personal factor and was one of the strongest predictors of a successful response to the proactive care programs. SRH has been shown to reliably predict survival in populations, even when adjusted for known risk factors (Idler \& Benyamini, I997). Self-rated health incorporates more than just absence of a disease; it reflects health-related quality of life, and implies a holistic perception of one's health status (Idler \& Benyamini, I997). This corresponds with our findings as those with a low self-reported health suffered from more geriatric conditions (falls, urinary incontinence, mood, and depression), had more comorbidities, and had a higher number of medications in chronic use compared to those with a high self-rated health (data not shown, available on request). SRH is influenced by higher levels of physical activity (Brenowitz et al., 2014), and is associated with a positive perception of aging (Beyer, Wolff, Warner, Schüz, \& Wurm, 20I5). Beyer and colleagues (20I5) propose that a more positive perception of aging influences participation in physical activity which is turn is reflected in a better SRH over time (Beyer et al., 20I5). In contrast, a longitudinal study among 75 year old adultsshowed that less than excellent self-rated health predicted a decline in physical functioning, but poor physical functioning may not predict change in self-rated health (Brenowitz et al., 20I4). Thus, identifying the actual directionality of these relationships requires additional research.

Table 5. Multivariate Logistic Regression Stratified by Study Population

\begin{tabular}{|c|c|c|c|c|c|c|c|}
\hline \multirow[b]{2}{*}{ Predictors } & \multicolumn{3}{|c|}{ U-PROFIT N = 230} & \multirow[b]{2}{*}{ Predictors } & \multicolumn{3}{|c|}{$H C P N=231$} \\
\hline & $O R$ & $95 \% \mathrm{Cl}$ & $p$ value & & OR & $95 \% \mathrm{Cl}$ & $p$ value \\
\hline Age & 0.98 & $0.89-1.07$ & .64 & Age & 0.99 & $0.91-1.07$ & .77 \\
\hline Female & 0.79 & $0.40-1.54$ & .48 & Female & 1.37 & $0.63-2.91$ & .41 \\
\hline Using a walking aid & 0.84 & $0.37-1.92$ & .67 & Using a walking aid & 0.76 & $0.31-1.86$ & .54 \\
\hline Better self-rated health & 1.38 & $0.65-2.90$ & .40 & Better self-rated health & 1.52 & $0.76-3.03$ & .24 \\
\hline Number of comorbidities & 0.81 & $0.59-1.11$ & .19 & Number of comorbidities & 0.92 & $0.63-1.34$ & .67 \\
\hline Functional status at baseline $\mathrm{a}^{\mathrm{a}}$ & 0.97 & $0.84-1.13$ & .68 & Functional status at baseline $\mathrm{a}^{\mathrm{a}}$ & 1.01 & $0.86-1.16$ & .93 \\
\hline
\end{tabular}




\section{Original Article}

Pain within the function domain of the ICF (WHO, 200I), and fewer falls, within the health condition domain of the ICF, were significantly associated with a successful response in the univariate analysis, but were not independently associated with the outcome in the multivariate analysis. Evidence has shown that community-dwelling older people with chronic pain have a higher risk for developing disability over time compared with those without pain (Eggermont et al., 20I4). Therefore, early detection and treatment of pain should be considered as one of the priority goals of a nurse-led care program aimed to maintain independent living in older adults. This would necessitate a careful assessment of the chronic disease and condition domain to identify its underlying cause, if feasible. Meanwhile, falls may serve as a marker for using a walking aid and is an important health condition that affects daily functioning. In the literature, the association between using a walking aid, impaired balance, and falls among older people has been confirmed (Van Kan et al., 2009).

Within the ICF model, level of education can also be classified as a personal factor that influences daily functioning, but one that is influenced by the social and environment domains. Although measuring education in the oldest-old population might not have been the most sensitive proxy measure of socioeconomic status, we observed that level of education appeared to have some influence on a successful response. People with a higher education might respond better to this type of care, which is in line with the results from a subgroup analysis in the U-PROFIT trial. A number of possible explanations for the relationship between educational level and daily functioning can be considered. First, several studies have shown that low education, a measure of socioeconomic status, is associated with adverse outcomes such as morbidity, frailty, and institutionalization (Fried et al., 200I; Barnett et al., 20I2; Hoogendijk et al., 20I4). This may be explained by biomedical factors such as the type and number of chronic conditions, behavior (e.g., unhealthy lifestyle), psychosocial factors (e.g., mental health status), or lack of resources to deal with multiple concurrent demands (Hoogendijk et al., 20I4). Furthermore, low education is associated with low health literacy and modifying the intervention based on the level of health literacy should be considered in the future (Bostock \& Steptoe, 20I2). We do not assume that the higher educational level as such explains the greater benefit of the intervention in terms of daily functioning, but rather that other determinants linked to educational level, such as health literacy or communication skills, contribute to the better outcome. There is some evidence that the quality of communication between patients and doctors and nurses is an important factor in determining patients' compliance (Aelbrecht et al., 20I5). Therefore, the communication between the nurses and the patients could have played a role in these types of interventions. In the future, the utilization of more sensitive measures, such as accumulated wealth, or area of living, may be more appropriate measures.

Although the ICF enables a biopsychosocial perspective, and can be seen as the overarching framework of both interven- tions, it is less easy to operationalize. The individual interventions, focusing on self-care factors such as pain, each utilized a theory that was clinically grounded, person centered, and adaptable to the situation. The HCP focuses on empowerment and self-management with a clear family approach. Interventions were tailored, flexible and decision-trees were used by the nurses. The U-PROFIT approach was more clinical based using evidence-based guidelines; the nurses delivered the intervention based on the individual care needs of older adults. Results of the qualitative study of U-PROFIT showed that the relationship with the nurse, timing of visits, and provided care, as well as tailoring the care to individual needs, were identified as conditions related to appreciation. If the care was well regarded, older adults were more likely to accept it, which helped them anticipate changes or handle consequences of aging more easily (Bleijenberg et al., 20I5). Despite the usefulness of the ICF as an overarching framework, the findings suggest that other theoretical approaches such as relationship, empowerment, and connectedness may contribute to enhanced outcomes in the oldest-old population.

\section{LIMITATIONS AND STRENGTHS}

Some methodological limitations need to be acknowledged. First, the primary outcome of this study was daily functioning, measured with either the Katz-I3 or OARS-I3. Despite the fact that the items of both scales were comparable, both instruments are not sensitive enough to capture small changes over time. Therefore, it is possible that subtle changes in function between baseline and follow-up were not observed in either population (Table Si, found with the online version of this article). Further, use of summary score across individuals could cancel out intra-individual patterns of trajectory change that would facilitate our understanding of specific personal factors associated with a positive response to the interventions. Second, the two studies differed in follow-up period (HCP 9 months and U-PROFIT I2 months) as well as in the type and intensity of the intervention. The components of the HCP intervention were based on health promotion, empowerment, and family centeredness, whereas the U-PROFIT approach was more conventionally clinical assessment and treatment using evidence-based guidelines. Here, the nurses focused on the geriatric problems and provided integrated care. Although both of these intervention programs were designed to meet the needs of the family and assure continuity of care, subtle differences in the philosophical approaches or the ways in which the interventions were carried out could have influenced the outcomes. Moreover, in the HCP trial the nurses who delivered the program (i.e., the interventionists) were advanced practice nurses, whereas the U-PROFIT, registered nurses with additional training in geriatrics-gerontological nursing delivered the intervention. It remains unclear how these interventionrelated factors affected the observed findings. Third, we were unable to observe strongly significant factors that were independently associated with a positive response to the 
interventions. This may be due to a lack of power resulting from defining congruent data sets that could be combined. Finally, this study does not provide insights into why the intervention may be more beneficial to specific groups of patients such as those who rate their health as excellent or good and to and those who have relatively less comorbidities. A process evaluation to examine the actual "dose delivered" (e.g., detailed interventions of the nurse) and intervention fidelity may provide valuable information to explain our findings (Moore et al., 20I5). Further, factors associated with lower education, such as concurrent life demands that prevent individuals from focusing on their health and taking on new health habits, need to be explored.

In spite of these limitations, to our knowledge this is the first study that explored the relationship between patient characteristics in the oldest-old (8o+ years) and successful response to nurse-led care from an international perspective. Both trials were able to include a substantial number of $80+$ participants. Including the oldest-old population in trials is challenging and this group is often excluded due to the large number of inclusion or exclusion criteria (Ferrucci et al., 2004). This secondary data analysis allows us to better understand who benefits most from the intervention. This is rarely considered in other trials. Despite the fact that randomized trials are frequently reported as the most suitable design to evaluate an intervention, a limitation is that treatment effects are reported on mean group level (Mody et al., 2008). However, patients do not have the same likelihood of responding to a given treatment, especially a heterogeneous population of older people. This requires an individualized tailored approach. Therefore, the results of this study are valuable as we identified patient characteristics associated with successful response. Although both RCTs were conducted in different countries, the intervention, outcome measures, and context in terms of health care system, insurance, and access to primary care were comparable which improves the generalizability of these findings.

\section{IMPLICATIONS FOR CLINICAL PRACTICE}

The results contribute to the existing body of knowledge on how multicomponent, community-based, nurse-led intervention programs are able to slow the decline in daily functioning, even in the oldest-old population. Promising elements of these multicomponent, evidence-based programs include screening, assessment, intensive case management, and coordination provided by a multidisciplinary team of researchers (Markle-Reid et al., 2006). Early detection of older adults at risk for decline and knowledge regarding how to provide integrated care that focuses on the individual care needs of older adults is recommended to obtain maximum benefit. Health professionals in primary care, such as nurses and primary care physicians, should be adequately prepared and trained to deliver such integrated care to older adults in the community (WHO, 20I5). Greater effort is needed to develop training programs and evidence-based tools for healthcare professionals to enhance the provision of care to this population.

\section{IMPLICATIONS FOR FUTURE RESEARCH}

The findings suggest that more research is needed to optimize nurse-led primary care interventions that are successful in preserving daily functioning, especially in the oldest-old with multiple comorbidities and low education. A modified nurse-led care program may result in substantial intervention effects that will enable older people to live independently at home as long as possible. Future intervention studies are needed to examine the optimal type, dose, and intensity of the intervention in the individual patient. These studies should consider a theoretical framework that assesses the interplay between behavioral, biological, social and environmental determinants, rather than focusing on a single biomedical influence. This type of care is appreciated when the relationship with the nurse and timing of the intervention are tailored to the individual (Bleijenberg et al., 20I5). Furthermore, a person-centered care approach and empowerment seem essential elements.

The concept of self-rated health should be considered for use in daily care support decisions. Moreover, these interventions should be optimally tailored to the individual older person. The involvement of patients and providers when designing the intervention is therefore recommended. Qualitative studies exploring the care needs in the oldest-old population will contribute to the design of successful tailored interventions in the future.

In conclusion, two large randomized trials evaluating a proactive nurse-led primary care programs showed preservation of daily functioning for more than half of the oldest-old population. Our analysis suggests that a nurse-led care program could be beneficial in those $80+$ older adults with a better self-rated health and few comorbidities. Unraveling individual characteristics associated with a successful response provides detailed information on who benefits most. WVN

\section{LINKING EVIDENCE TO ACTION}

- Unraveling the characteristics associated with a successful response provides important information for further refining and targeting an intervention to obtain maximum effectiveness.

- Greater effort is needed to modify interventions to the oldest-old with multimorbidity and low education.

- Health professionals in primary care, such as nurses and primary care physicians, should be adequately prepared and trained to deliver integrated care to older adults in the community. 


\section{Author information}

Nienke Bleijenberg, Assistant Professor, Julius Center for Health Sciences and Primary Care, Department of General Practice, University Medical Center Utrecht, Utrecht, The Netherlands; Lorenz Imhof, Head of Research Institute of Nursing, Zurich University of Applied Sciences, Winterthur, Switzerland; Romy Mahrer-Imhof, Professor, Research Institute of Nursing Zurich University of Applied Sciences (ZHAW), Winterthur, Switzerland; Margaret I. Wallhagen, Director, John A. Hartford Center of Gerontological Nursing Excellence, University of California San Francisco, School of Nursing, Department of Physiological Nursing, San Francisco, CA, USA; Niek J. de Wit, Professor, Julius Center for Health Sciences and Primary Care, Department of General Practice, University Medical Center Utrecht, Utrecht, The Netherlands; Marieke J. Schuurmans, Professor, Department of Rehabilitation, Nursing Science and Sports Medicine, University Medical Center Utrecht, Utrecht, The Netherlands

The authors would like to thank H. Hediger, MSc, and Dr. N.P.A Zuithoff for their statistical support.

Address correspondence to Dr. Nienke Bleijenberg, Julius Center for Health Sciences and Primary Care, Department of General Practice, University Medical Center Utrecht, Heidelberglaan I0o, Str 6.I3I - Room 6.I05, PO Box 85500, 3508 GA Utrecht, The Netherlands; n.bleijenberg@umcutrecht.nl

Accepted 2I February 2016

Copyright (C) 2017, Sigma Theta Tau International

\section{References}

Aelbrecht, K., Rimondini, M., Bensing, J., Moretti, F., Willems, S., Mazzi, M., \& . . . Deveugele, M. (20I5). Quality of doctorpatient communication through the eyes of the patient: Variation according to the patient's educational level. Advances in Health Sciences Education, 20(4), 873-884.

Akaike, H. (I974). A new look at the statistical model identification. Automatic Control, IEEE Transactions On, 19(6), 716-723.

Barnett, K., Mercer, S. W., Norbury, M., Watt, G., Wyke, S., \& Guthrie, B. (20I2). Epidemiology of multimorbidity and implications for health care, research, and medical education: A cross-sectional study. The Lancet, $380(9836)$, 37-43.

Beswick, A. D., Rees, K., Dieppe, P., Ayis, S., Gooberman-Hill, R., Horwood, J., \& Ebrahim, S. (2008). Complex interventions to improve physical function and maintain independent living in elderly people: A systematic review and meta-analysis. The Lancet, 371(96I4), 725-735.

Beyer, A., Wolff, J. K., Warner, L. M., Schüz, B., \& Wurm, S. (20I5). The role of physical activity in the relationship between self-perceptions of ageing and self-rated health in older adults. Psychology \& Health, 30(6), 67I-685.

Bleijenberg, N., Drubbel, I., Schuurmans, M. J., Ten Dam, V. H., Zuithoff, N. P. A., Numans, M. E., \& De Wit, N. J. (20I6). The effectiveness of a proactive patient-centered primary care programme on daily functioning of frail older patients; a cluster randomised controlled trial. Journal of the American Geriatrics Society, 64(9), I779-I788.
Bleijenberg, N., Drubbel, I., ten Dam, V. H., Numans, M. E., Schuurmans, M. J., \& de Wit, N. J. (20I2). Proactive and integrated primary care for frail older people: design and methodological challenges of the Utrecht primary care PROactive Frailty Intervention Trial (U-PROFIT). BMC Geriatrics, 12(I), I6.

Bleijenberg, N., Boeije, H. R., Onderwater, A. T., \& Schuurmans, M. J. (2OI5). Frail older adults' experiences with a proactive, nurse-led primary care program: A qualitative study. Journal of Gerontological Nursing, 41(9), 20-29.

Bleijenberg, N., Ten Dam, V. H., Drubbel, I., Numans, M. E., Wit, N. J., \& Schuurmans, M. J. (20I3). Development of a proactive care program (U-CARE) to preserve physical functioning of frail older people in primary care. Journal of Nursing Scholarship, 45(3), 230-237.

Bleijenberg, N., Ten Dam, V. H., Steunenberg, B., Drubbel, I., Numans, M. E., Wit, N. J., \& Schuurmans, M. J. (2013). Exploring the expectations, needs and experiences of general practitioners and nurses towards a proactive and structured care programme for frail older patients: A mixed-methods study. Journal of Advanced Nursing, 69(10), 2262-2273.

Bostock, S., \& Steptoe, A. (20I2). Association between low functional health literacy and mortality in older adults: Longitudinal cohort study. BMJ (Clinical Research Ed.), 344, er6o2. doi:ı.ıi36/bmj.ei6o2

Brenowitz, W. D., Hubbard, R. A., Crane, P. K., Gray, S. L., Zaslavsky, O., \& Larson, E. B. (2OI4). Longitudinal associations between self-rated health and performance-based physical function in a population-based cohort of older adults. PloS ONE, 9(II), eiri76r.

Chatterji, S., Byles, J., Cutler, D., Seeman, T., \& Verdes, E. (20I5). Health, functioning, and disability in older adults-present status and future implications. The Lancet, 385(9967), 563575 .

Donders, A. R. T., van der Heijden, Geert J., M. G., Stijnen, T., \& Moons, K. G. (2006). Review: A gentle introduction to imputation of missing values. Journal of Clinical Epidemiology, 59(го), ro87-1091.

Drubbel, I., De Wit, N. J., Bleijenberg, N., Eijkemans, R. J., Schuurmans, M. J., \& Numans, M. E. (2013). Prediction of adverse health outcomes in older people using a frailty index based on routine primary care data. The Journals of Gerontology, Series A, Biological Sciences and Medical Sciences, 68(3), 30I-308. doi:Io.Io93/gerona/glsi6r

Eggermont, L. H., Leveille, S. G., Shi, L., Kiely, D. K., Shmerling, R. H., Jones, R. N., \& . . Bean, J. F. (20I4). Pain characteristics associated with the onset of disability in older adults: The maintenance of balance, independent living, intellect, and zest in the elderly Boston study. Journal of the American Geriatrics Society, 62(6), I007-IOI6.

Fairhall, N., Sherrington, C., Kurrle, S. E., Lord, S. R., Lockwood, K., \& Cameron, I. D. (20I2). Effect of a multifactorial interdisciplinary intervention on mobility-related disability in frail older people: Randomised controlled trial. BMC Medicine, 10(I),I2O. doi:IO.II86/I74I-70I5-IO-I20

Ferrucci, L., Guralnik, J. M., Studenski, S., Fried, L. P., Cutler, G. B. Jr, \& Walston, J. D. (2004). Designing randomized, controlled trials aimed at preventing or delaying functional decline and disability in frail, older persons: A consensus report. Journal of the American Geriatrics Society, 52(4), 625-634.

Fillenbaum, G. G., \& Smyer, M. A. (I98I). The development, validity, and reliability of the OARS multidimensional functional 
assessment questionnaire. Journal of Gerontology, $36(4), 428-$ 434 .

Fried, L. P., Tangen, C. M., Walston, J., Newman, A. B., Hirsch, C., \& Gottdiener, J. (200I).. . . Cardiovascular Health Study Collaborative Research Group. Frailty in older adults: Evidence for a phenotype. The Journals of Gerontology. Series A, Biological Sciences and Medical Sciences, 56 (3), Mi46-Mi56.

Gnjidic, D., Hilmer, S. N., Blyth, F. M., Naganathan, V., Waite, L., Seibel, M. J., \& . . Le Couteur, D. G. (20I2). Polypharmacy cutoff and outcomes: Five or more medicines were used to identify community-dwelling older men at risk of different adverse outcomes. Journal of Clinical Epidemiology, 65(9), 989-995.

Harrell, F., Lee, K. L., \& Mark, D. B. (1996). Tutorial in biostatistics multivariable prognostic models: Issues in developing models, evaluating assumptions and adequacy, and measuring and reducing errors. Statistics in Medicine, 15, 36I-387.

Hoogendijk, E. O., Van Hout, H. P., Heymans, M. W., Van Der Horst, Henriëtte, E., Frijters, D. H., \& . . Huisman, M. (20I4). Explaining the association between educational level and frailty in older adults: Results from a I3-year longitudinal study in the Netherlands. Annals of Epidemiology, 24(7), 538-544.

Idler, E. L., \& Benyamini, Y. (I997). Self-rated health and mortality: A review of twenty-seven community studies. Journal of Health and Social Behavior, 38(I), 2I-37.

Imhof, L., Naef, R., Wallhagen, M. I., Schwarz, J., \& Mahrer-Imhof, R. (2OI2). Effects of an advanced practice nurse in-home health consultation program for community-dwelling persons aged 80 and older. Journal of the American Geriatrics Society, 6o(I2), 2223223I.

Imhof, L., Naef, R., Mahrer-Imhof, R., \& Petry, H. (20II). SpitexPlus: Assessment und fortgeschrittene Pflegeinterventionen fur zuhause lebende alte Menschen und ihre Familien [Spitex Plus: Assessment of and specialised nursing care for elderly and their families living in the community]. Pflege, 24(I), 43-56. doi:IO.I024/IOI2-5302/a000090

Laan, W., Zuithoff, N., Drubbel, I., Bleijenberg, N., Numans, M., De Wit, N., \& Schuurmans, M. (20I4). Validity and reliability of the katz-I5 scale to measure unfavorable health outcomes in community-dwelling older people. The Journal of Nutrition, Health Q Aging, 18(9), 848-854.

Markle-Reid, M., Browne, G., \& Gafni, A. (2013). Nurse-led health promotion interventions improve quality of life in frail older home care clients: Lessons learned from three randomized trials in Ontario, Canada. Journal of Evaluation in Clinical Practice, 19(I), II8-I3I.

Markle-Reid, M., Browne, G., Weir, R., Gafni, A., Roberts, J., \& Henderson, S. R. (2006). The effectiveness and efficiency of home-based nursing health promotion for older people: A review of the literature. Medical Care Research and Review, 63(5), 53I569 .

Markle-Reid, M., Weir, R., Browne, G., Roberts, J., Gafni, A., $\&$ Henderson, S. (2006). Health promotion for frail older home care clients. Journal of Advanced Nursing, 54(3), 38I-395. doi:Io.IIII/j.I365-2648.2006.038I7.x

Metzelthin, S. F., Van Rossum, E., De Witte, L. P., Ambergen, A. W., Hobma, S. O., Sipers, W., \& Kempen, G. I. (2013). Effectiveness of interdisciplinary primary care approach to reduce disability in community dwelling frail older people: Cluster randomised controlled trial. BMJ: British Medical Journal, 347, $\mathrm{f}_{52} 6_{4}$.

Mody, L., Miller, D. K., McGloin, J. M., Freeman, M., Marcantonio, E. R., Magaziner, J., \& Studenski, S. (2008). Recruitment and retention of older adults in aging research. Journal of the American Geriatrics Society, 56(12), 2340-2348.

Moore, G. F., Audrey, S., Barker, M., Bond, L., Bonell, C., Hardeman, W., \& Baird, J. (20I5). Process evaluation of complex interventions: Medical research council guidance. BMJ (Clinical Research Ed.), 350, hI258. doi:Io.I136/bmj.hı258

Prince, M. J., Wu, F., Guo, Y., Robledo, L. M. G., O'Donnell, M., Sullivan, R., \& Yusuf, S. (2015). The burden of disease in older people and implications for health policy and practice. The Lancet, $385(9967)$, 549-562.

Rechel, B., Grundy, E., Robine, J., Cylus, J., Mackenbach, J. P., Knai, C., \& McKee, M. (20I3). Ageing in the European Union. The Lancet, 381(9874), I3I2-I322.

Stall, N., Nowaczynski, M., \& Sinha, S. K. (20I4). Systematic review of outcomes from home-based primary care programs for homebound older adults. Journal of the American Geriatrics Society, 62(I2), 2243-225I.

Steverink, N., Slaets, J., Schuurmans, H., \& Van Lis, M. (200I). Measuring frailty. Development and testing of the Groningen Frailty Indicator (GFI). Gerontologist, 41, 236-237.

Van Kan, G. A., Rolland, Y., Andrieu, S., Bauer, J., Beauchet, O., Bonnefoy, M., . . . \& Nourhashemi, F. (2009). Gait speed at usual pace as a predictor of adverse outcomes in communitydwelling older people an International Academy on Nutrition and Aging (IANA) Task Force. The Journal of Nutrition, Health Q Aging, 13(I0), 88I-889.

Weber, G. (2002). Study of adult well-being. [European Statistics on Accidents at Work report]. Vienna, Austria: University of Vienna.

Weinberger, M., Samsa, G. P., Schmader, K., Greenberg, S. M., Carr, D. B., \& Wildman, D. S. (I992). Comparing proxy and patients' perceptions of patients' functional status: Results from an outpatient geriatric clinic. Journal of the American Geriatrics Society, 40(6), 585-588.

World Health Organization. (2015). World report on ageing and health. Ageing and life-course. Retrieved from http://www. who.int/ageing/publications/world-report-2015/en/

World Health Organization. (200I). International classification of functioning, disability and health. Geneva, Switzerland: Author.

doi IO.IIII/Wvn.I2235

WVN 2OI7;I4:210-222

\section{SUPPORTING INFORMATION}

Additional supporting information may be found in the online version of this article at the publisher's web site:

Figure Si. ICF model (WHO, 200I).

Figure S2. Example evidence-based flowchart cognition as used in the U-PROFIT trial.

Table SI. Mean (SD) and Median (IQR) Katz-I3 and OARS-I3 at Each Measurement* 